of drug resistance. However, knowledge of strain genotype is no less clinically and epidemiologically relevant. A superspreading strain might be marked with other pathobiologically important features. In the case presented here (indeed emerging and MDR), the NGS-based in silico spoligotyping would confuse the MDR/extensively drug resistant SIT266 with "less dangerous" SIT264. To be precise, the revealed discrepancy is not inherent to the NGS technology itself. Although the general limitation of the use of short sequencing reads to infer repetitive genome regions is known, it did not pose a problem in our study. However, both bioinformatics tools predicted the spoligoprofile solely from the presence or absence of spacer sequences and did not take into account a "hiding" effect exerted by a putative IS6110 insertion on adjacent spacer under classical spoligotyping.

In conclusion, we suggest that an accurate NGSbased prediction requires an integrative approach to all relevant information obtained by in silico analysis of a given genome locus. In particular, not only presence of CRISPR spacers but also presence and location of potentially interfering IS6110 insertion(s) should be considered for correct NGS-based assignment to internationally recognized spoligotypes.

This project received funding from Russian Science Foundation (grant 14-14-00292). E.C. acknowledges additional partial support from St. Petersburg State University (grant 1.38.253.2015).

\section{References}

1. Zalutskaya A, Wijkander M, Jureen P, Skrahina A, Hoffner S. Multidrug-resistant Myobacterium tuberculosis caused by the Beijing genotype and a specific T1 genotype clone (SIT No. 266) is widely transmitted in Minsk. Int J Mycobacteriol. 2013;2:194-8. http://dx.doi.org/10.1016/j.ijmyco.2013.08.001

2. Mokrousov I, Vyazovaya A, Narvskaya O. Mycobacterium tuberculosis Latin American-Mediterranean family and its sublineages in the light of robust evolutionary markers. J Bacteriol. 2014;196:1833-41. http://dx.doi.org/10.1128/JB.01485-13

3. Narvskaya O, Mokrousov I, Otten T, Vishnevsky B. Molecular markers: application for studies of Mycobacterium tuberculosis population in Russia. In: Read MM, editor, Trends in DNA fingerprinting research. New York: Nova Science Publishers; 2005. p. 111-25.

4. Ignatova A, Dubiley S, Stepanshina V, Shemyakin I. Predominance of multi-drug-resistant LAM and Beijing family strains among Mycobacterium tuberculosis isolates recovered from prison inmates in Tula Region, Russia. J Med Microbiol. 2006;55:1413-8. http://dx.doi.org/10.1099/jmm.0.46575-0

5. Mokrousov I, Vyazovaya A, Solovieva N, Sunchalina T, Markelov Y, Chernyaeva E, et al. Trends in molecular epidemiology of drug-resistant tuberculosis in Republic of Karelia, Russian Federation. BMC Microbiol. 2015;15:279. http://dx.doi.org/ 10.1186/s12866-015-0613-3

6. Tracevska T, Jansone I, Baumanis V, Marga O, Lillebaek T. Prevalence of Beijing genotype in Latvian multidrug-resistant Mycobacterium tuberculosis isolates. Int J Tuberc Lung Dis. 2003; 7:1097-103.

7. Pardini M, Niemann S, Varaine F, Iona E, Meacci F, Orrù G, et al. Characteristics of drug-resistant tuberculosis in Abkhazia

(Georgia), a high-prevalence area in Eastern Europe. Tuberculosis (Edinb). 2009;89:317-24. http://dx.doi.org/10.1016/j. tube.2009.04.002

8. Mokrousov I, Rastogi N. Spacer-based macroarrays for CRISPR genotyping. Methods Mol Biol. 2015;1311:111-31. http://dx.doi.org/10.1007/978-1-4939-2687-9_7

9. Xia E, Teo YY, Ong RT. SpoTyping: fast and accurate in silico Mycobacterium spoligotyping from sequence reads. Genome Med. 2016;8:19. http://dx.doi.org/10.1186/s13073-016-0270-7

10. Sekizuka T, Yamashita A, Murase Y, Iwamoto T, Mitarai S, Kato S, et al. TGS-TB: total genotyping solution for Mycobacterium tuberculosis using short-read whole-genome sequencing. PLoS One. 2015;10:e0142951. http://dx.doi.org/ 10.1371/journal.pone.0142951

Address for correspondence: Igor Mokrousov, Laboratory of Molecular Microbiology, St. Petersburg Pasteur Institute, 14 Mira St, St. Petersburg, Russia; email: imokrousov@mail.ru

\title{
MERS-CoV Infection of Alpaca in a Region Where MERS-CoV is Endemic
}

\author{
Chantal B.E.M. Reusken, ${ }^{1}$ Chrispijn Schilp, ${ }^{1}$ \\ V. Stalin Raj, Erwin De Bruin, Robert H.G. Kohl, \\ Elmoubasher A.B.A. Farag, Bart L. Haagmans, \\ Hamad Al-Romaihi, Francois Le Grange, \\ Berend-Jan Bosch, Marion P.G. Koopmans
}

Author affiliations: Erasmus Medical Center, Rotterdam, the Netherlands (C.B.E.M. Reusken, V.S. Raj, E. De Bruin, R.H.G. Kohl, B.L. Haagmans, M.P.G. Koopmans); Al Wabra Wildlife Preservation, Doha, Qatar (C. Schlip, F. Le Grange); Supreme Council of Health, Doha (E.A.B.A. Farag, H. Al-Romaihi); Utrecht University Faculty of Veterinary Medicine, Utrecht, the Netherlands (B.-J. Bosch)

\section{DOI: http://dx.doi.org/10.3201/eid2206.152113}

To the Editor: Accumulating evidence indicates that dromedaries (Camelus dromedarius) are a reservoir for zoonotic transmission of Middle East respiratory syndrome coronavirus (MERS-CoV). Although numerous studies have looked at other livestock in the Middle East region, evidence for MERS-CoV infection has only been found in dromedaries (1). Extensive and continuous circulation of MERS-CoV occurs in the Al Shahaniya region of Qatar, most likely because of the presence of an international camel racing track and numerous barns holding camels (2,3). In April 2015, we investigated the MERS-CoV infection status of 15 healthy alpacas (Vicugna pacos) in a herd of 20 animals and 10 healthy dromedaries in a herd of 25

\footnotetext{
${ }^{1}$ These authors contributed equally to this article.
} 
animals at a farm in this region (online Technical Appendix, http://wwwnc.cdc.gov/EID/article/22/6/15-2113-Techapp1.pdf).

The herds were located at a distance of $\approx 200 \mathrm{~m}$ from each other within the barn complex and were cared for by the same animal workers, who lived in a common house between the herds at the complex. Both the alpacas and camels were kept as hobby animals.

Serum samples were collected from all 25 animals. Nasal swabs were collected from all camels, whereas nasal, rectal, and oral swab specimens were collected only from a subset of the alpacas (online Technical Appendix) because of logistical constraints. The serum samples were tested for IgG antibodies reactive with the S1 antigens of MERS$\mathrm{CoV}$ and severe acute respiratory syndrome coronavirus (SARS-CoV), and titers were calculated as described previously $(4,5)$. MERS-CoV reactivity was confirmed by using a $90 \%$ plaque-reduction neutralization test $\left(\mathrm{PRNT}_{90}\right)$ (3). Swab specimens were analyzed for MERS-CoV RNA by a screening PCR targeting the upE gene (6). MERS-CoVspecific antibodies were detected in all alpacas and all but 1 camel by protein microarray; reciprocal titers ranged from 49 to 773 for the alpacas and were $\geq 1,280$ for the camels (Figure, panel A). PRNT $_{90}$ testing confirmed the presence of MERS-CoV-specific antibodies; reciprocal neutralizing titers ranged from 80 to 320 for the alpacas and from 80 to $\geq 2560$ for 9 camels (Figure, panel B). All swab specimens were negative by PCR (online Technical Appendix). None of the serum samples were reactive to SARS-CoV S1. The microarray was also conducted for bovine $\mathrm{CoV}$ and human CoV-229E antigens, which were used as a proxy for the

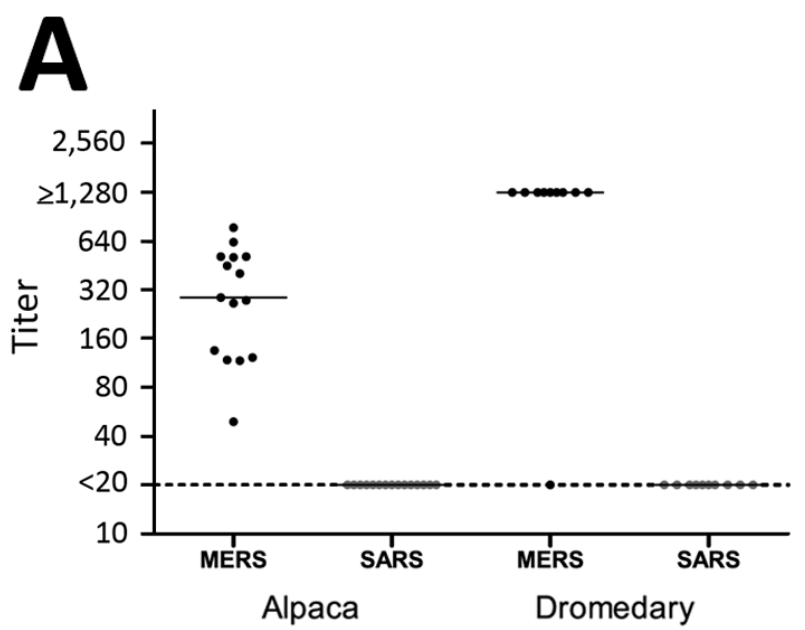

serologically closely related dromedary betacoronavirus- 1 HKU23 and 229E-related camelid alphacoronaviruses, respectively (7). Positive binding was detected for both antigens in alpaca and dromedary (data not shown).

Our observations prove the susceptibility of alpacas for natural MERS-CoV infection and lay the foundation for future studies to determine the potential of alpacas as another livestock reservoir for MERS-CoV. The alpacas in this study were the only alpacas in Qatar at the time and were located in a region where MERS-CoV is endemic. In a previous study, by using the same microarray technology, we found no evidence for MERS-CoV infection in alpacas from regions where MERS-CoV is not endemic (4). Although a study by Eckerle et al. demonstrated the potential of MERS-CoV to infect alpaca kidney cells in vitro (8) and alignment of mammalian DPP4 indicate that the 14 residues interacting with the MERS-CoV receptor binding domain of alpaca DPP4 are identical to that of dromedary DPP4 (online Technical Appendix), the in vivo susceptibility of alpacas remained to be determined.

The observed natural susceptibility of alpacas to MERS-CoV infection potentiates a broadening of the geographic range of MERS-CoV circulation to areas with large populations of alpacas. Alpacas are New World camelids, and the worldwide population of alpacas is estimated at 3 million animals, with $\approx 94 \%$ living in the high Andean regions of South America (Peru, Bolivia, Chile and Argentina), of which most are in Peru (constituting $\approx 88 \%$ of the world alpaca population) (http://lib.icimod.org/ record/23682). Alpacas are increasingly being kept outside

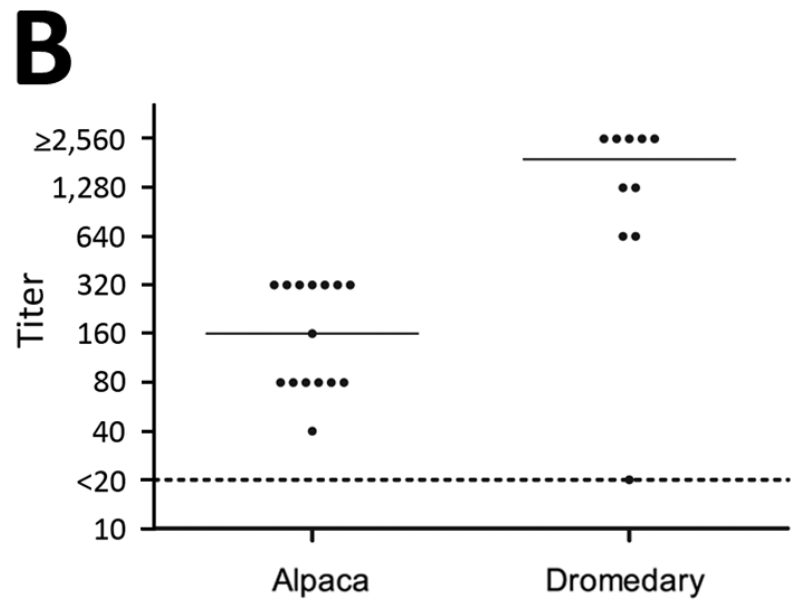

Figure. Column scatterplots of MERS-CoV reactivity of serum samples from alpaca $(n=15)$ and dromedaries $(n=10)$ in the Al Shahaniya region of Qatar, April 2015. A) Plot of alpaca and dromedary serum titers of antibodies specific for S1 antigens of 2 coronaviruses as determined by protein microarray. Titers were defined as the interpolated serum concentration that provoked a response half-way on a concentration-response curve between the minimum and maximum signal and were calculated from the inflection point of a 4-step dilution series $(1: 20$ to 1:1,280) as described previously (5). B) Plot of alpaca and dromedary serum titers of MERS-CoV neutralizing antibodies as determined by $\mathrm{PRNT}_{90}$. The highest serum dilution neutralizing $90 \%$ of plaque formation is depicted. For both panels, solid lines indicate median, and dotted lines indicate detection limit. MERS, Middle East respiratory syndrome; CoV, coronavirus; $\mathrm{PRNT}_{90}, 90 \%$ plaque-reduction neutralization test; SARS, severe acute respiratory syndrome. 
South America, mainly for their fleece, with estimated numbers in 2014 reaching 230,000 in the United States (http://lib.icimod.org/record/23682), 35,000 in the United Kingdom (http://www.bas-uk.com), and 150,000 in Australia (http://www.alpaca.asn.au). Although MERS-CoV has not been found in camelids other than dromedaries outside the Arabian Peninsula so far (9), our observations raise the question of whether other camelids could become infected if MERS-CoV were introduced to regions with large populations of alpacas and possibly other closely related camelids of the genera Lama, Vicugna, and Camelus.

Because the date of infection of the alpacas and camels in this study is not known, we cannot speculate on the level of susceptibility of alpacas versus dromedaries based on the observed differences in antibody titers, which were lower in alpacas. It remains to be determined whether alpacas, in parallel with dromedaries, will actually shed MERS-CoV and are capable of independent maintenance of the virus in their population. Differences in susceptibility to viral pathogens between New and Old World camelids have been observed before (10). Therefore, understanding the risk requires further assessment of the reservoir competence of alpacas for MERS-CoV (e.g., through experimental infections) and an assessment of MERS-CoV-related viruses present in alpacas and other camelids in different parts of the world.

\section{Acknowledgments}

We thank M. Al-Hajri, Supreme Council of Health, and the workers at the Al Maha farm and the Al Wabra Wildlife Preservation, in particular H.E. Sheikh Saoud Mohamed Bin Ali Al-Thani and A. Abdi, for support of this study.

This study was funded in part by the European Union FP7 projects ANTIGONE (contract no. 278976) and was supported by a grant from the Dutch Scientific Research Organization (NWO grant no. 91213066).

\section{References}

1. Chan JF, Lau SK, To KK, Cheng VC, Woo PC, Yuen KY. Middle East respiratory syndrome coronavirus: another zoonotic betacoronavirus causing SARS-like disease. Clin Microbiol Rev. 2015;28:465-522. http://dx.doi.org/10.1128/CMR.00102-14

2. Haagmans BL, Al Dhahiry SH, Reusken CB, Raj VS, Galiano M, Myers R, et al. Middle East respiratory syndrome coronavirus in dromedary camels: an outbreak investigation. Lancet Infect Dis. 2014;14:140-5. http://dx.doi.org/10.1016/S1473-3099(13)70690-X

3. Reusken CB, Farag EA, Haagmans BL, Mohran KA, Godeke GJV V, Raj S, et al. Occupational exposure to dromedaries and risk for MERS-CoV infection, Qatar, 2013-2014. Emerg Infect Dis. 2015;21:1422-5. http://dx.doi.org/10.3201/eid2108.150481

4. Reusken CB, Haagmans BL, Müller MA, Gutierrez C, Godeke GJ, Meyer B, et al. Middle East respiratory syndrome coronavirus neutralising serum antibodies in dromedary camels: a comparative serological study. Lancet Infect Dis. 2013;13:859-66.

http://dx.doi.org/10.1016/S1473-3099(13)70164-6
5. Koopmans M, de Bruin E, Godeke GJ, Friesema I, van Gageldonk R, Schipper M, et al. Profiling of humoral immune responses to influenza viruses by using protein microarray. Clin Microbiol Infect. 2012;18:797-807. http://dx.doi.org/10.1111/ j.1469-0691.2011.03701.x

6. Corman VM, Eckerle I, Bleicker T, Zaki A, Landt O, Eschbach-Bludau M, et al. Detection of a novel human coronavirus by real-time reverse-transcription polymerase chain reaction. Euro Surveill. 2012;17:20285.7. Sabir JS, Lam TT, Ahmed MM, Li L, Shen Y, Abo-Aba SE, et al. Co-circulation of three camel coronavirus species and recombination of MERS-CoVs in Saudi Arabia. Science. 2016;351:81-4. http://dx.doi.org/10.1126/ science.aac 8608

8. Eckerle I, Corman VM, Müller MA, Lenk M, Ulrich RG, Drosten C. Replicative capacity of MERS coronavirus in livestock cell lines. Emerg Infect Dis. 2014;20:276-9. http://dx.doi.org/ 10.3201/eid2002.131182

9. Chan SM, Damdinjav B, Perera RA, Chu DK, Khishgee B, Enkhbold B, et al. Absence of MERS-coronavirus in Bactrian camels, southern Mongolia, November 2014. Emerg Infect Dis. 2015;21:1269-71. http://dx.doi.org/10.3201/eid2107.150178

10. Wernery U, Kinne J. Foot and mouth disease and similar virus infections in camelids: a review. Rev Sci Tech. 2012;31:907-18.

Address for correspondence: Chantal B.E.M. Reusken, Viroscience Department, Erasmus Medical Center, PO Box 2040, Rotterdam 3000 CA, the Netherlands; email: c.reusken@erasmusmc.nl

\section{Cryptococcus gattii VGIIb-like Variant in White-Tailed Deer, Nova Scotia, Canada}

\section{David P. Overy, ${ }^{1}$ Scott McBurney, ${ }^{1}$ Anne Muckle, Lorraine Lund, P. Jeffery Lewis, Robert Strang}

Author affiliations: Atlantic Veterinary College, University of Prince Edward Island, Charlottetown, Prince Edward Island, Canada (D.P. Overy, S. McBurney, A. Muckle, L. Lund, P.J. Lewis); Department of Health and Wellness, Halifax, Nova Scotia, Canada (R. Strang)

\section{DOI: http://dx.doi.org/10.3201/eid2206.160081}

To the Editor: Cryptococcus gattii is a fungal pathogen that is emerging in the Pacific Northwest of North America. In Nova Scotia, Canada, previously not recognized as a $C$. gattii-endemic area, a variant strain similar to VGIIb caused cryptococcosis with nasopulmonary, lymph node and central nervous system involvement in a free-ranging, yearling white-tailed deer (Odocoileus virginianus). The deer was found in the village of Greenwood (latitude 44.9717246; longitude -64.9341295 ) on July 14, 2014. The deer exhibited behavioral and neurologic abnormalities, including

\footnotetext{
${ }^{1}$ These authors contributed equally to this article.
} 